Research Paper

\title{
High quality in vitro expansion of human endothelial progenitor cells of human umbilical vein origin
}

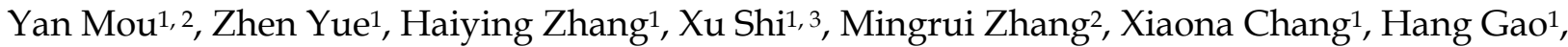 \\ Ronggui $\mathrm{Li}^{1}$ and Zonggui Wang ${ }^{2 凶}$ \\ 1. Key Laboratory of Pathobiology, Ministry of Education, Norman Bethune College of Medicine, Jilin University, Changchun, China; \\ 2. The Second Hospital of Jilin University, Changchun, China; \\ 3. The First Hospital of Jilin University, Changchun, China.
}

$\triangle$ Corresponding authors: Dr. Ronggui Li, The Key Laboratory of Pathobiology, Ministry of Education, Norman Bethune College of Medicine, Jilin University, Changchun, 130021, P.R. China. Tel.: 86-43185619481; E-mail: lirg@jlu.edu.cn and Dr. Zonggui Wang, The Second Hospital of Jilin University, Changchun, P.R. China. Tel.: 86-43188796114; E-mail: zonggui@jlu.edu.cn.

(c) Ivyspring International Publisher. This is an open access article distributed under the terms of the Creative Commons Attribution (CC BY-NC) license (https://creativecommons.org/licenses/by-nc/4.0/). See http://ivyspring.com/terms for full terms and conditions.

Received: 2016.10.30; Accepted: 2017.01.14; Published: 2017.02.25

\begin{abstract}
The limited availability of qualified endothelial progenitor cells (EPCs) is a major challenge for regenerative medicine. In the present study, we isolated human EPCs from human umbilical vein endothelial cells (HUVECs) by using magnetic micro-beads coated with an antibody against human CD34. Flow cytometric assay showed that majority of these cells expressed VEGFR2 (KDR), CD34 and CD133, three molecular markers for early EPCs. It was also found that a bioreactor micro-carrier cell culture system (bio-MCCS) was superior to dish culture for in vitro expansion of EPCs. It expanded more EPCs which were in the early stage, as shown by the expression of characteristic molecular markers and had better angiogenic potential, as shown by matrix-gel based in vitro angiogenesis assay. These results suggest that HUVECs might be a novel promising resource of EPCs for regenerative medicine and that a bio-MCCS cell culture system might be broadly used for in vitro expansion of EPCs.
\end{abstract}

Key words: endothelial progenitor cells; micro-carrier; angiogenesis; cell therapy.

\section{Introduction}

Endothelial progenitor cells (EPCs) are stem/ progenitor cells with the potential to differentiate into mature endothelial cells [1]. In contrast with mature endothelial cells, EPCs have a greater ability to proliferate and to contribute to angiogenesis [2-5]. Accumulated evidence suggests an importance of EPCs for neovascularization and vascular remodeling [6-8]. Moreover, EPCs have been used to treat vascular diseases [9], promoting reconstruction of ischemic regions [10], and have the potential for regenerative medicine therapy $[11,12]$. However, the limited availability of EPCs has been the major restriction to their broad application for cell research and regenerative medicine.

Early and late stage EPCs can be characterized by surface markers and biological properties [13], but no unique definitive marker for EPCs has been described. However, three molecular markers, CD133, VEGFR2 (KDR), and CD34 are widely accepted as characteristics of early stage EPCs [13]. EPCs have been mainly isolated from bone marrow (BM) and peripheral blood (PB), as well as umbilical cord blood. BM-derived EPCs express CD133, VEGFR2 (KDR), and CD34, representing more immature progenitors in an early stage $[13,14]$. On the other hand, PB-derived EPCs can be obtained through repetitive collection, which is not possible with BM sources. However, EPCs isolated from PB lose CD133 and CD34, representing more mature EPCs in late stage [14]. Thus, more work is required to find alternative EPCs sources with abundant cell numbers in the early stage. Among these alternative sources are human 
umbilical vein endothelial cells (HUVECs) which represent an earlier stage of development, and have also been widely used for experimental research [15]. Furthermore, it has been shown that HUVECs can be passaged for about 40 population doublings in vitro. More importantly, it has been reported that populations of HUVECs include EPCs [16]. However, to our knowledge, until now the means for isolating EPCs from HUVECs has not been described.

EPCs are adhesive cells which occupy the bottom of the culture dish. Conventionally, EPCs cultured on dishes require repetitive passaging once proliferating to confluence, which is time consuming and expensive. Also, culture procedures may cause cell differentiation and reduce angiogenic potential [17]. Therefore, a strategy to provide a robust source of functional EPCs would be highly advantageous. The aim of this study was to isolate human EPCs from HUVECs, to expand them in vitro on a large scale, and to analyze their angiogenesis capacity.

\section{Materials and Methods}

\section{Materials}

Endothelial cell medium (ECM, Cat. No. 1001) and endothelial cell growth supplement (ECGS, Cat. No. 1052) were purchased from the ScienCell Research Laboratories (San Diego, USA). bFGF (Cat. No. ZG-DGFYL-7-02) was purchased from ZeGuang Bio (Beijing, China). Collagenase II (Cat. No. 17101015) was purchased from Gibco BRL (Rockville, USA). Human CD34 MicroBead Kit (Cat No. 130046702) was purchased from Miltenyi Biotec. (Bergisch Gladbach, Germany). Fetal bovine serum (FBS, Cat. No. SH30071.03) was from HyClone Inc. (Logan, USA). Fluorescent antibodies anti-KDR-PE (Cat. No. 560494) and anti-CD34-FITC (Cat. No. 555821) were from BD Pharmingen (San Jose, USA), and anti-CD133-APC (Cat. No. 130090826) was purchased from Miltenyi Biotec. (Bergisch Gladbach, German). In vitro Angiogenesis Assay Kit (Cat. No. ECM625) was purchased from Millipore (Billerica, USA). Calcein-AM (Cat. No. sc-203865) was purchased from Santa Cruz Biotechnology, Inc. (Dallas, USA). Porcine gelatin micro-beads (Culcell tispher-G, Cat. No.1001296469) were purchased from Percell Biolytica AB (Åstorp, Sweden).

\section{Isolation of HUVECs}

Human umbilical cords were collected from healthy volunteers according to a protocol approved by the Ethics Review Board of the Second Hospital of Jilin University. HUVECs were obtained from human umbilical cord veins by a chemical digestion method as reported previously [18]. The cells were cultured in
ECM supplemented with 5\% FBS, 1\% ECGS and $2 \mathrm{ng} / \mathrm{ml} \mathrm{bFGF}$. The cells were plated in $6 \mathrm{~cm}$ diameter dishes, at a seeding density of $5 \times 10^{5}$ cells/dish, incubated for $24 \mathrm{~h}$ with a change of culture medium, and cultured for 7 days, with medium change every other day on tissue culture dishes in the presence of $5 \% \mathrm{CO}_{2}$ and $37^{\circ} \mathrm{C}$.

\section{Separation of EPCs}

The CD34-positive EPCs were separated from primary HUVECs by using magnetic micro-beads coated with an antibody against human CD34 following the manufacture's guideline (Cat. No. 130046702, Miltenyi). Briefly, a single-cell suspension was prepared and the cell density of each sample was $2 \times 10^{6}$ cells every separation. The cells were added to $100 \mu \mathrm{L}$ of magnetic micro-beads coated with an antibody against human CD34 and incubated for 30 minutes at $4^{\circ} \mathrm{C}$. Cells were washed and resuspended in $500 \mu \mathrm{l}$ buffer (a solution containing PBS, pH 7.2, $0.5 \%$ FBS and $2 \mathrm{mM}$ EDTA). The suspension was placed into a column in the magnetic field of a cell separator. CD34 negative cells (which passed through the column) were discarded. After removing the column from the separator, the magnetically isolated CD34-positive cells were collected into a suitable collection tube.

\section{EPCs in vitro expansion in the Bio-MCCS and dish culture}

A bioreactor micro-carrier cell culture system (bio-MCCS) was used to expand the EPCs in vitro. Briefly, separated EPCs were digested with $0.25 \%$ trypsin when they became confluent, harvested by centrifugation, and counted. Approximately $1 \times 10^{6}$ cells were evenly inoculated onto $0.25 \mathrm{~g}$ of rehydrated micro-beads. In vitro culture was performed in the bioreactor using $50 \mathrm{ml} \mathrm{ECM}$, supplemented with $5 \%$ FBS, $1 \%$ ECGS and $2 \mathrm{ng} / \mathrm{ml}$ bFGF at $37^{\circ} \mathrm{C}$ and $5 \% \mathrm{CO}_{2}$. The Cellspin was set at $20 \mathrm{rpm}$, with a 5-min running time/ 59-min stop intervals. One-third of the medium was exchanged with fresh medium every 3 days for a total of 12 days expansion culture. As a control, the cells were plated in tissue culture dishes of $6 \mathrm{~cm}$ diameter at an initial seeding density of $5 \times 10^{4}$ cells per dish and incubated for $24 \mathrm{~h}$ with a change of culture medium, every other day. The cells were passaged every 4 days during the 12 days culture period.

\section{Flow cytometric analysis}

The surface markers of the cells were analyzed using flow cytometry. Cells were detached with $0.25 \%$ trypsin and incubated for 20 minutes at $4^{\circ} \mathrm{C}$ at manufacturer-recommended concentrations with fluorescent antibodies: anti-KDR-PE $(20 \mu l$ per test, a test $=1 \times 10^{6}$ cells in a $100-\mu l$ experimental sample), 
anti-CD34-FITC (20ul per test), and anti-CD133-APC (10 $\mu 1$ per test) as EPCs markers [13]. Fluorescent isotype-matched antibodies were used as negative controls. Cells were analyzed with a flow cytometer with $\geq 10,000$ events stored. The emitted green fluorescence of anti-CD34-FITC (FL1) and red fluorescence of anti-KDR-PE, anti-CD133-APC (FL3) were detected at excitation wavelengths of 488 and $546 \mathrm{~nm}$, respectively, and at emission wavelengths of 525 and $647 \mathrm{~nm}$, respectively.

\section{In vitro angiogenesis assay}

The angiogenic potential of the cells was evaluated by a Matrix-gel in vitro angiogenesis assay technique. The assay was performed with a detailed procedure as described previously [19]. For quantification, the values for the pattern recognition, branch point and total capillary tube length were determined following the manufacturer's guidelines (ECM625; Millipore).

\section{Statistical analysis}

SPSS 19.0 software was utilized to analyze the data. Student's $t$ test was used to analyze the significance of any differences between two groups. $\chi^{2}$ was used to analyze the qualitative data. The statistical significance was defined as $p<0.05$.

\section{Results}

\section{Isolation of EPCs from human umbilical vein}

We obtained HUVECs from human umbilical veins using a conventional chemical digestion method. Fig. 1 shows representative microscopic appearances. Freshly isolated cells attached to the bottom of the culture dish and appeared as spindle or elliptical shapes. Endothelial cell islands remained compact after culture for 1 day. Subsequently, they expanded and a monolayer of the endothelial lineage occupied the plastic surface by day 7 . This had a characteristic cobblestone-like morphology (Fig. 1). These results are consistent with traits of endothelial lineage cells [14, 20], indicating that the isolated cells are HUVECs.

VEGFR2 (KDR), CD34 and CD133 expression in isolated HUVECs were analyzed with flow cytometry and these data appear in Fig. 2. Most HUVECs expressed VEGFR2 (KDR) and CD133 with lesser expression of CD34 (Fig.2, HUVECs). Based on the accepted standard, that early stage EPCs express VEGFR2 (KDR), CD133, and CD34 as molecular markers [13, 14]. These results indicate that these cultures contained early EPCs, although these were not the majority of cells in HUVECs cell cultures. To isolate the EPCs in an early stage, magnetic micro-beads coated with an antibody against human CD34 were applied. As expected, the proportion of CD34 positive cells separated this way was significantly increased from about $8 \%$ before (HUVECs in Fig. 2) to $79 \%$ after separation (EPCs in Fig. 2). The majority of the EPCs expressed VEGFR2 (KDR), CD34 and CD133, as shown in Fig. 2. Thus, human EPCs were successfully isolated from HUVECs and majority of them belong to the early stage.
Day 1

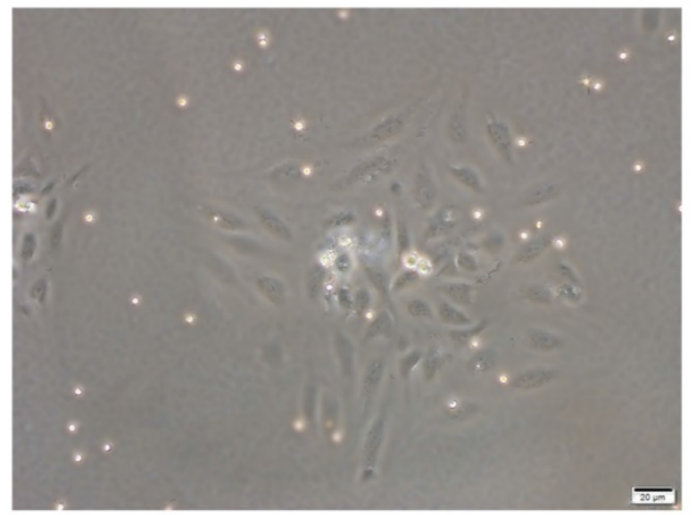

Day 7

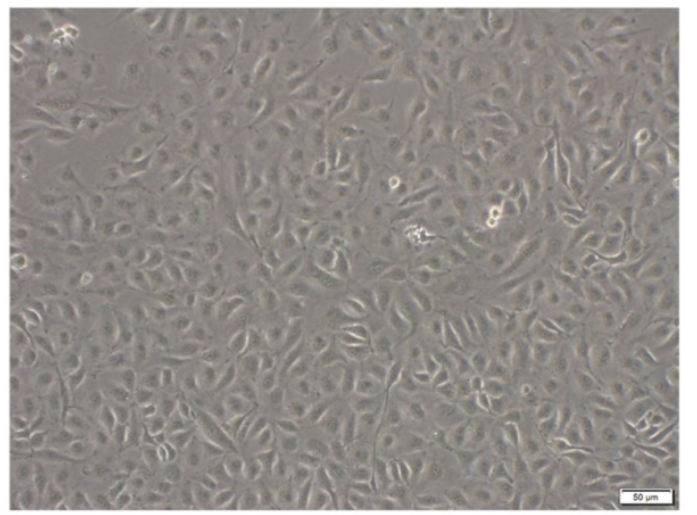

Figure 1. Microscopic appearance of isolated HUVECs in primary culture. HUVECs were isolated from human umbilical vein by classic collagenase digestion method. Phase-contrast microscopic appearance are shown. 


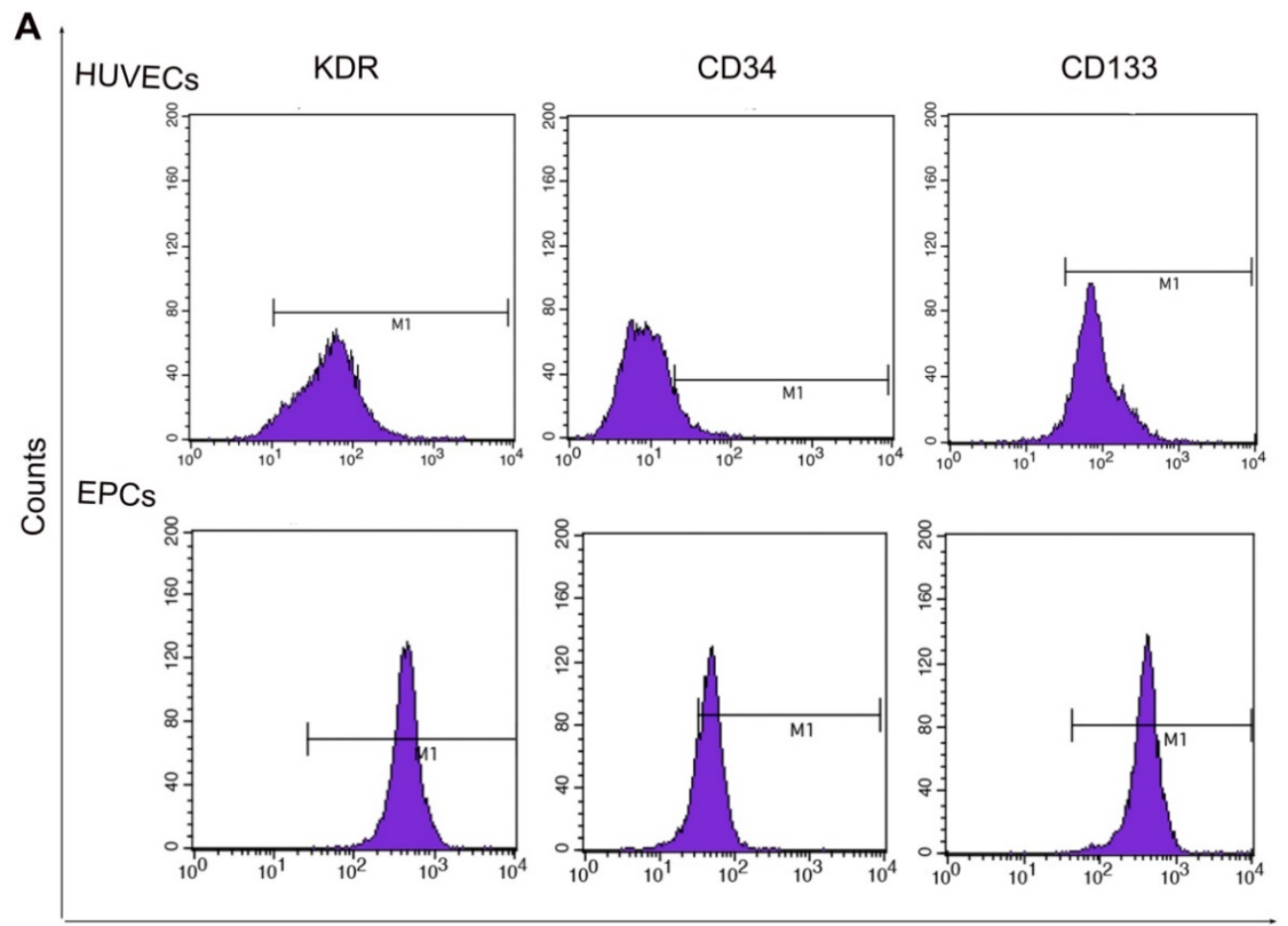

Fluorescence intensity

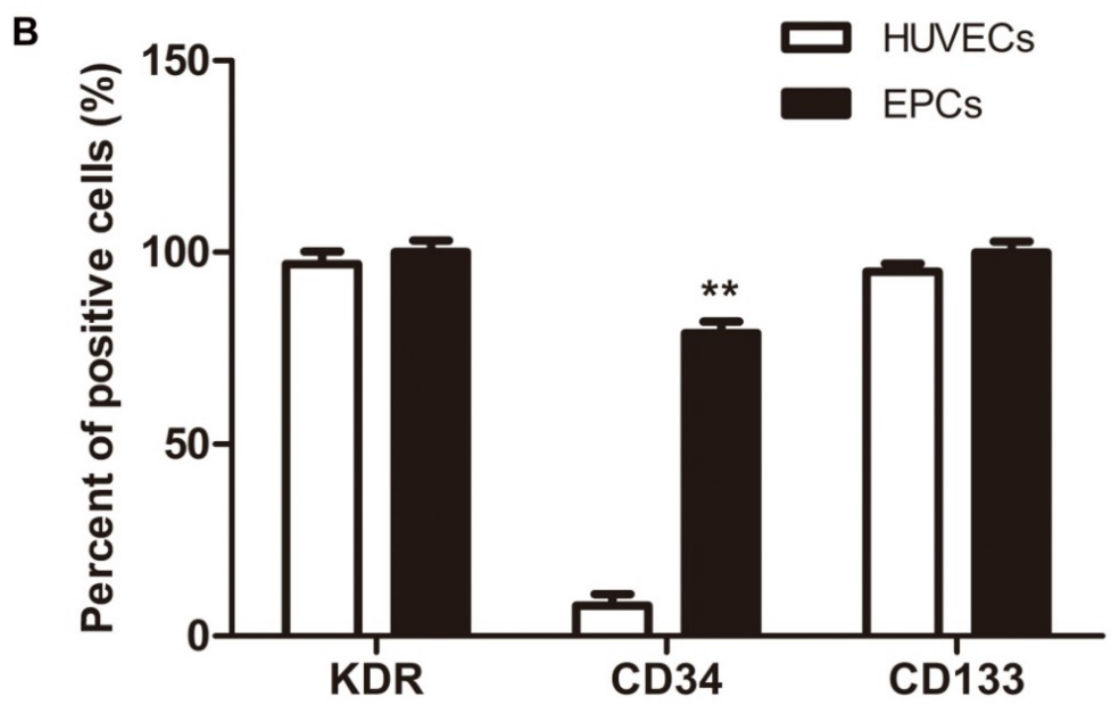

Figure 2. Expression of KDR, CD34 and CD133 in HUVECs and EPCs. The CD34+ cells were separated from CD34- cells by using magnetic micro-beads coated with an antibody against human CD34. The expression of molecular markers was analyzed by flow cytometry. Representative data are shown in $A$ and statistical data are shown in $\mathrm{B}$. $\mathrm{N}=3$, **p $<0.01$ versus HUVECs.

\section{EPCs expansion in vitro}

To obtain abundant and high quality human EPCs, we expanded the cells in vitro using a bio-MCCS culture. The conventional dish culture was used as a control to compare the efficiency of the two expansion methods. Fig. 3A shows that EPCs cultured with bio-MCCS could attach to and proliferate on micro-beads. Growth curves for each method were plotted (Fig. 3B). EPCs cultured with bio-MCCS generated more cells without passaging for 12 days of culture. Whereas EPCs cultured on dishes were not as abundant by day 12 and these had been passaged 3 times. One expanded culture with MCCS is equivalent to fourteen dishes with dish culture $\left(11.7 \times 10^{6}\right.$ from one bottle versus $0.8 \times 10^{6}$ from one dish). Thus, the bio-MCCS method is superior to 
conventional dish culture in the total harvest cell numbers and expansion efficiency.

We next measured early EPC marker expression after expansion by using flow cytometry. Fig. 4A shows representative data and Fig. $4 \mathrm{~B}$ shows the statistical results. The percentage of cells expressing VEGFR2 (KDR), CD34 and CD133 in EPCs expanded with the bio-MCCS (MCCS in Fig.4) was significantly higher than that expanded with dish culture (Dish in Fig.4). The results indicated that the bio-MCCS culture technique had great advantage over dish culture in maintaining the cells in the early stage when they were used to expand EPCs. This percentage also decreased after expansion with both methods, when compared with freshly isolated EPCs, as shown in Fig.2.

An in vitro angiogenesis assay was used to evaluate the angiogenic potential of expanded EPCs, based on their ability to form tubular networks [21, 22]. Fig. 5A shows representative microscopic appearances. Statistical data are shown in B, C and D. Closed polygons and/ or complex mesh-like structures formed in both cell types (Fig. 5B), indicating that both methods offered cells with angiogenic traits. However, EPCs expanded with bio-MCCS formed more branch points $(p<0.01$, Fig. $5 \mathrm{C})$ and had longer tubes $(p<0.01$, Fig. 5D) compared with EPCs harvested in dish culture. These data indicate that the bio-MCCS technique preserves potent angiogenesis compared with dish culture. Taken together, these results indicate that a bio-MCCS culture was superior to the dish culture for in vitro expansion of EPCs, by its efficiency, maintaining the cells in early stage and supporting more angiogenesis of the cells, suggesting its importance in the in vitro expansion of the cells.

A

Day 1
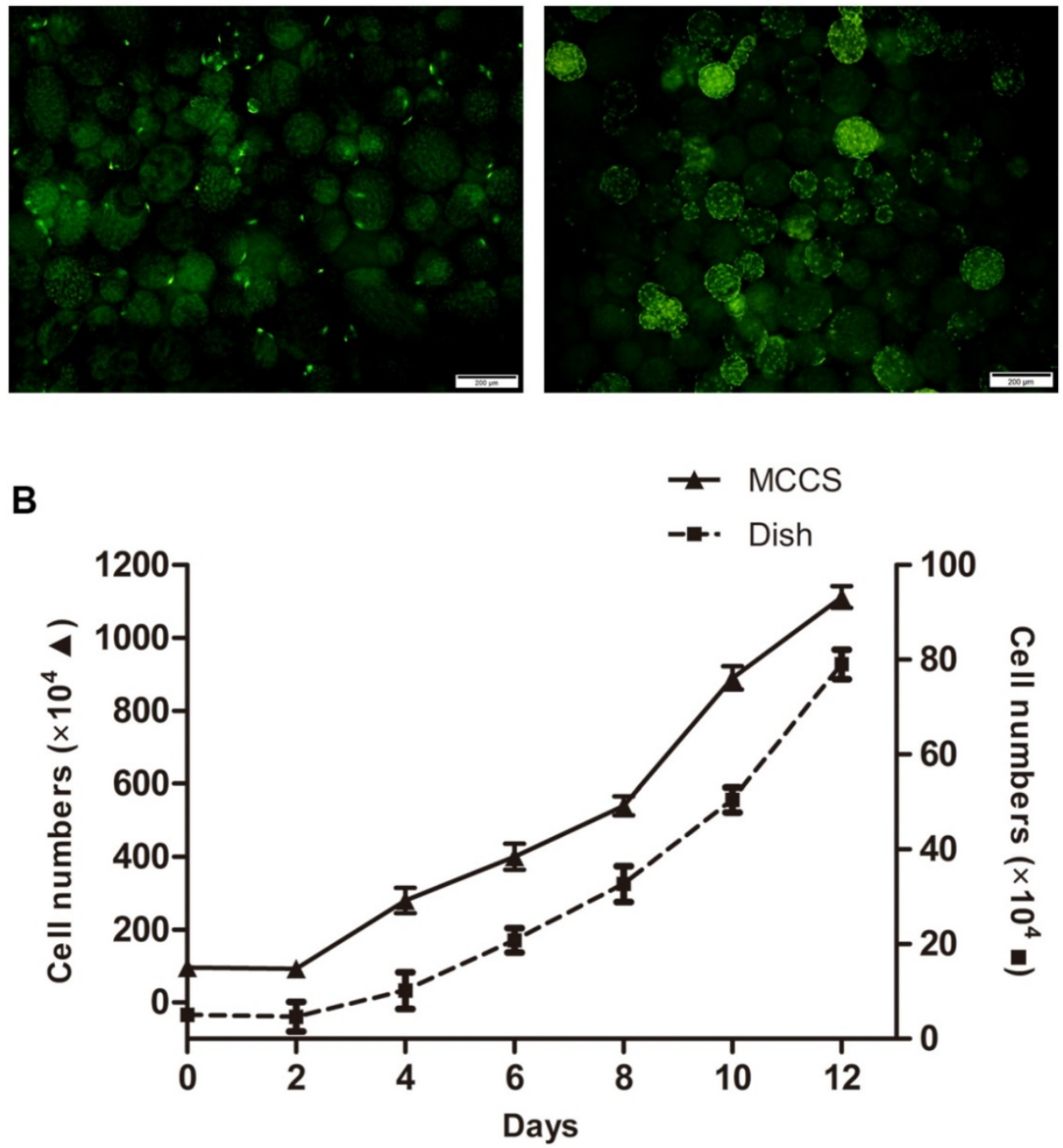

Figure 3. In vitro expansion of EPCs with bio-MCCS and dish culture. The bio-MCCS and dish culture methods were used for EPCs expansion. Representative microscopic appearance of bio-MCCS culture are shown in A. Cell growth curves for two methods are shown in B. Data are presented as the mean \pm SD. $N=3$. 

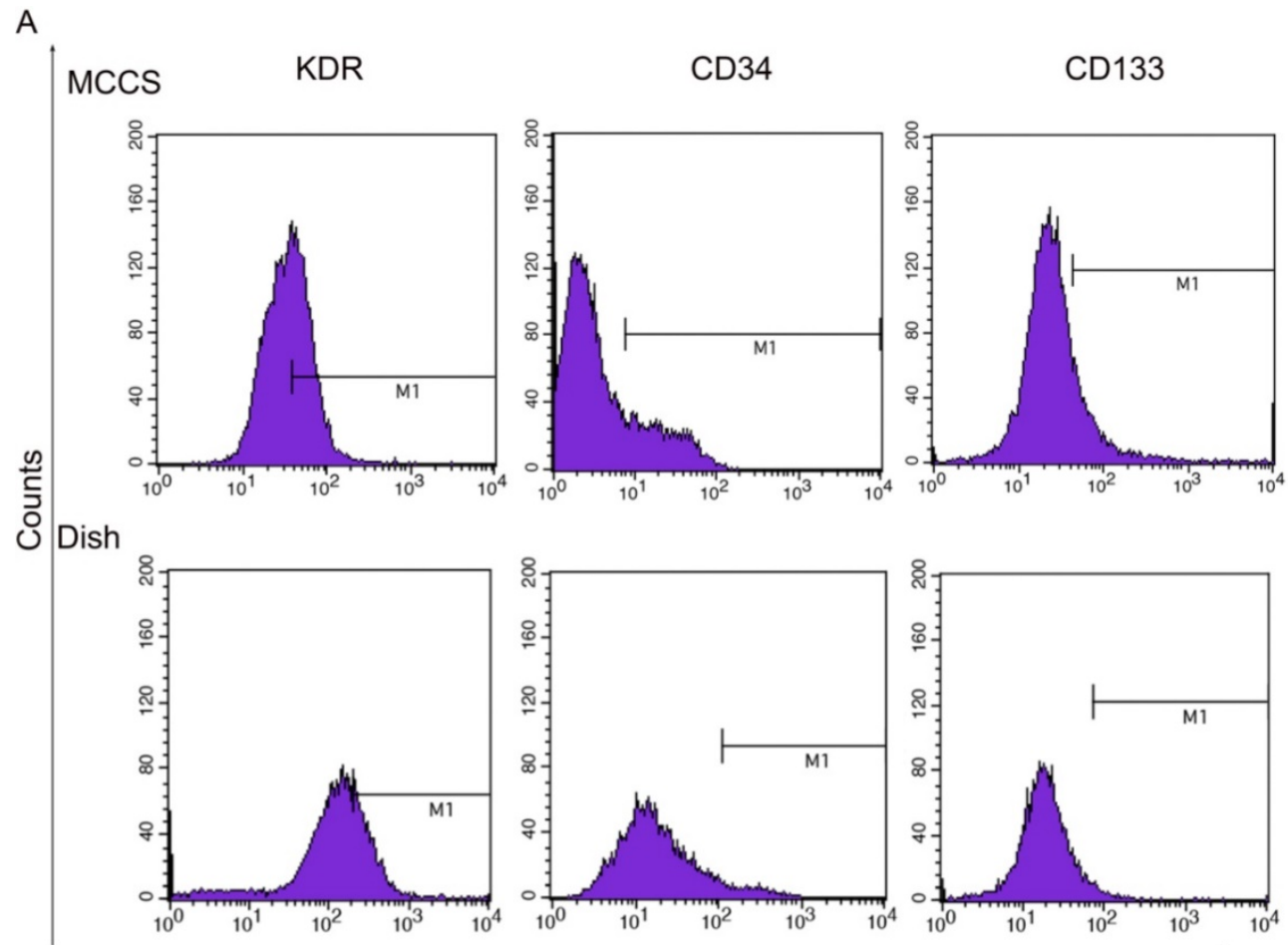

B

Fluorescence intensity

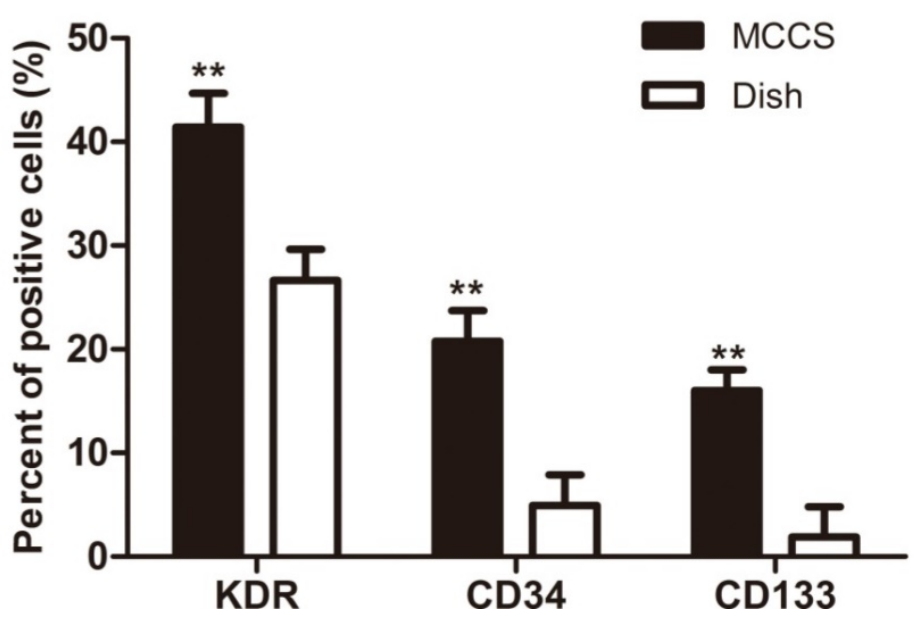

Figure 4. Expression of KDR, CD34 and CD133 of expanded EPCs. EPCs were expanded for 12 days and flow cytometry was used to quantify marker expression. Representative data are shown in $A$ and statistical data are shown in $\mathrm{B} . \mathrm{N}=3, *_{p}<0.01$ versus dish cultured cells.

\section{Discussion}

Here, we obtained HUVECs from human umbilical veins, and these cells had growth features, morphology and surface markers characteristic of endothelial lineage cells. Most of these freshly isolated HUVECs expressed VEGFR2 (KDR), consistent with previous reports that HUVECs expressed VEGFR2 (KDR), as a molecular marker for endothelial cells [23, 24]. Interestingly, these cells also expressed CD133, a molecular marker for early stem/ progenitor cells. It has been reported that established HUVECs cell lines do not express CD133 [23, 24] and this result was also noted in our previous study (unpublished data). Until now, no report on CD133 expression in primary cultured HUVECs has been reported. Our results indicate that CD133 is expressed in freshly isolated HUVECs, but that this molecular marker is lost in established cell lines, suggesting that freshly isolated HUVECs have some characteristics of stem/ progenitor cells, but that these are gradually lost during passage in culture. 
A

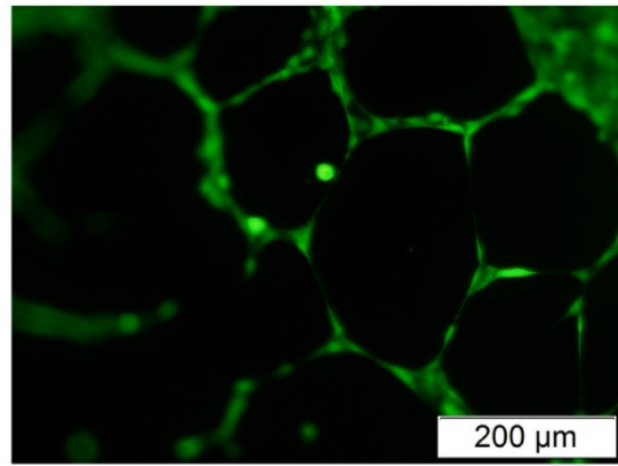

MCCS

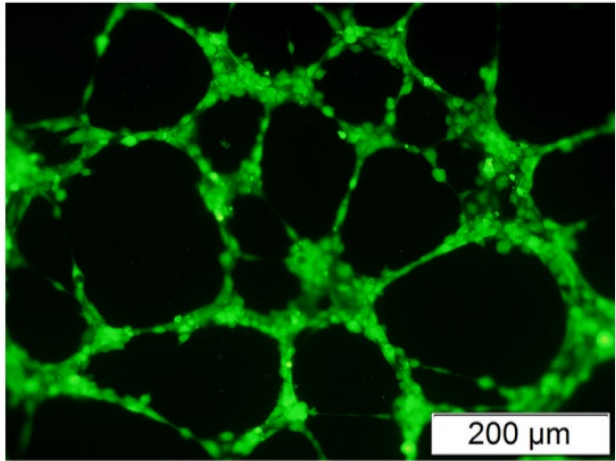

C

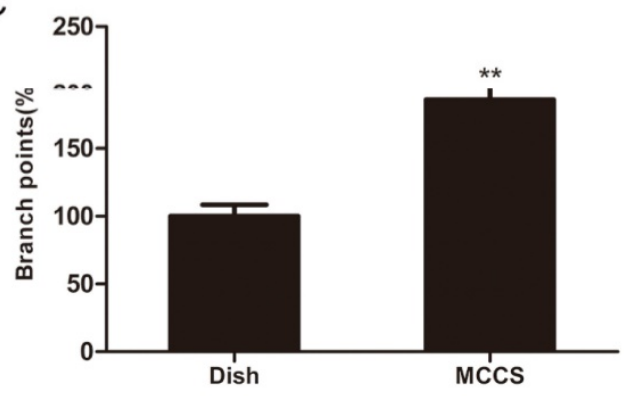

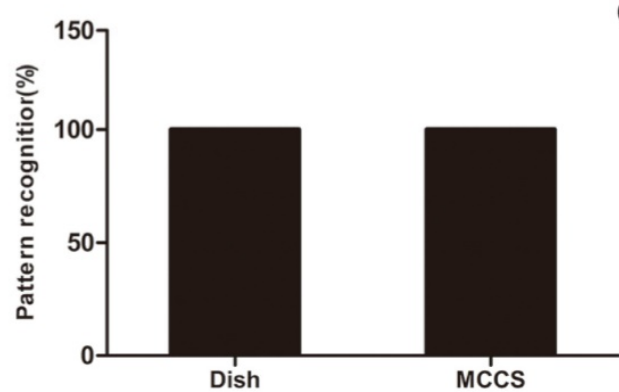

D

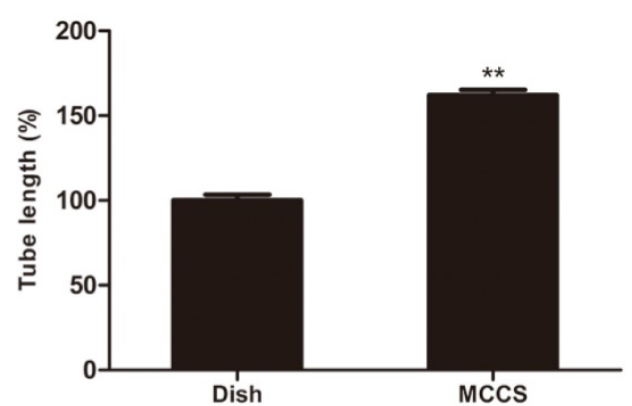

Figure 5. In vitro angiogenesis of expanded EPCs. EPCs were expanded for 12 days and angiogenesis was measured by a Matrix-gel based in vitro angiogenesis assay. The cell staining and the values quantification for the pattern recognition, branch point and total capillary tube length are described in the Methods section. Data are expressed relative to dish cultured cells. Representative microscopic appearances are shown in $A$. Statistical results are shown in B, $C$ and $D$, respectively. $N=$ 5 , **p $<0.01$ versus dish cultured cells.

By using magnetic micro-beads coated with an antibody against human CD34, we successfully isolated human EPCs. The majority of them expressed three molecular markers, VEGFR2 (KDR), CD34 and CD133, indicates that they belong to the early stage of EPCs. To our knowledge, this study is the first report on isolating human EPCs from primary cultures of HUVECs, suggesting that HUVECs might be a novel promising resource of EPCs for regenerative medicine.

Our results show that the bio-MCCS culture was superior to the dish culture for in vitro expansion. First, the expansion was more efficient. Secondly, more of the expanded cells were maintained in the early stage. Finally, the cells expanded with bio-MCCS technique were more capable of in vitro angiogenesis. The results indicated that the bio-MCCS culture technique had great advantage over dish culture in maintaining the cells in the early stage when they were used to expand EPCs. The percentage of cells expressing VEGFR2 (KDR), CD34 and CD133 was also less after expansion with the bio-MCCS culture, compared with freshly isolated EPCs, indicating further studies still required to optimize the culture condition, for example, supplementing the media with specific growth factors or cytokines, and coating the micro-beads with extracellular matrix. Even with this weak point, in the expanded EPCs described here, the percentages of cells positively expressing VEGFR2 (KDR), CD133 and CD34 is comparable to those of freshly isolated bone marrow [25], umbilical cord blood [23], and peripheral blood [26] derived human EPCs. These expanded EPCs described here formed complex tube-like structures in 
6 hours in a Matrix-gel based in vitro angiogenesis assay. It has been reported that 12 hours are required to form capillary-like structures for the EPCs derived from umbilical cord blood in the same assay system and in 6 hours only the cells line up with each other could be seen [27]. EPCs from BM [28] could adhere to and incorporate into the tube-like structures. In addition, EPCs from PB could attach to protrusions of endothelial cells around the tube-like structures [29].

\section{Conclusions}

We successfully isolated human EPCs from HUVECs, which belong to the early stage of the cells, by the expression of VEGFR2 (KDR), CD133 and CD34. The results suggest that EPCs from HUVECs might be a novel resource of cells for regenerative medicine. We also found that a bio-MCCS culture was superior to the dish culture for in vitro expansion of EPCs, by producing more cells, maintaining the early stage and supporting more angiogenesis of the cells. The result suggests that a bio-MCCS culture system described here might be broadly used for in vitro expansion of EPCs, or other cells of attached growth.

\section{Acknowledgments}

This study was supported in part by the National Natural Science Foundation of China (Grants: NSFC No. 21277057) and National Science Foundation of Jilin Province (No. 20130624003JC). We would like to express our great appreciation to Professor F. William Orr from the University of Manitoba in Canada for his great help in revising the manuscript.

\section{Competing Interests}

The authors have declared that no competing interest exists.

\section{References}

1. Asahara T, Murohara T, Sullivan A, Silver M, van der Zee R, Li T, et al. Isolation of putative progenitor endothelial cells for angiogenesis. Science (New York, NY). 1997; 275: 964-7.

2. Kirton JP, $\mathrm{Xu}$ Q. Endothelial precursors in vascular repair. Microvascular research. 2010; 79: 193-9.

3. Briasoulis A, Tousoulis D, Antoniades C, Papageorgiou N, Stefanadis C. The role of endothelial progenitor cells in vascular repair after arterial injury and atherosclerotic plaque development. Cardiovascular therapeutics. 2011; 29: 125-39.

4. Griese DP, Ehsan A, Melo LG, Kong D, Zhang L, Mann MJ, et al. Isolation and transplantation of autologous circulating endothelial cells into denuded vessels and prosthetic grafts: implications for cell-based vascular therapy. Circulation. 2003; 108: 2710-5.

5. Urbich C, Dimmeler S. Endothelial progenitor cells: characterization and role in vascular biology. Circulation research. 2004; 95: 343-53.

6. Caballero S, Sengupta N, Afzal A, Chang KH, Li Calzi S, Guberski DL, et al. Ischemic vascular damage can be repaired by healthy, but not diabetic, endothelial progenitor cells. Diabetes. 2007; 56: 960-7.

7. Melchiorri AJ, Bracaglia LG, Kimerer LK, Hibino N, Fisher JP. In Vitro Endothelialization of Biodegradable Vascular Grafts Via Endothelial Progenitor Cell Seeding and Maturation in a Tubular Perfusion System Bioreactor. Tissue engineering Part C, Methods. 2016; 22: 663-70.

8. Tongers J, Roncalli JG, Losordo DW. Role of endothelial progenitor cells during ischemia-induced vasculogenesis and collateral formation. Microvascular research. 2010; 79: 200-6.
9. Schmidt DE, Manca M, Hoefer IE. Circulating endothelial cells in coronary artery disease and acute coronary syndrome. Trends in cardiovascular medicine. 2015; 25: 578-87.

10. Peplow PV. Growth factor- and cytokine-stimulated endothelial progenitor cells in post-ischemic cerebral neovascularization. Neural regeneration research. 2014; 9: 1425-9.

11. Foster WS, Suen CM, Stewart DJ. Regenerative cell and tissue-based therapies for pulmonary arterial hypertension. The Canadian journal of cardiology. 2014; 30: 1350-60.

12. Wei L, Zhu W, Xia L, Yang Y, Liu H, Shen J, et al. Therapeutic effect of eNOS-transfected endothelial progenitor cells on hemodynamic pulmonary arterial hypertension. Hypertension research : official journal of the Japanese Society of Hypertension. 2013; 36: 414-21.

13. Asahara T, Kawamoto A, Masuda H. Concise review: Circulating endothelial progenitor cells for vascular medicine. Stem cells (Dayton, Ohio). 2011; 29: 1650-5.

14. Hristov M, Weber C. Endothelial progenitor cells: characterization, pathophysiology, and possible clinical relevance. Journal of cellular and molecular medicine. 2004; 8: 498-508.

15. Peng H, Chen L, Huang X, Yang T, Yu Z, Cheng G, et al. Vascular peroxidase 1 up regulation by angiotensin II attenuates nitric oxide production through increasing asymmetrical dimethylarginine in HUVECs. Journal of the American Society of Hypertension : JASH. 2016; 10: 741-51.e3.

16. Ingram DA, Mead LE, Moore DB, Woodard W, Fenoglio A, Yoder MC. Vessel wall-derived endothelial cells rapidly proliferate because they contain a complete hierarchy of endothelial progenitor cells. Blood. 2005; 105: 2783-6.

17. Kalka C, Masuda H, Takahashi T, Kalka-Moll WM, Silver M, Kearney M, et al. Transplantation of ex vivo expanded endothelial progenitor cells for therapeutic neovascularization. Proceedings of the National Academy of Sciences of the United States of America. 2000; 97: 3422-7.

18. Baudin B, Bruneel A, Bosselut N, Vaubourdolle M. A protocol for isolation and culture of human umbilical vein endothelial cells. Nature protocols. 2007; 2: 481-5.

19. Mou Y, Yue Z, Wang X, Li W, Zhang H, Wang Y, et al. OCT4 Remodels the Phenotype and Promotes Angiogenesis of HUVECs by Changing the Gene Expression Profile. International journal of medical sciences. 2016; 13: 386-94.

20. Bouis D, Hospers GA, Meijer C, Molema G, Mulder NH. Endothelium in vitro: a review of human vascular endothelial cell lines for blood vessel-related research. Angiogenesis. 2001; 4: 91-102.

21. Yoon $\mathrm{CH}$, Hur J, Park KW, Kim JH, Lee CS, Oh IY, et al. Synergistic neovascularization by mixed transplantation of early endothelial progenitor cells and late outgrowth endothelial cells: the role of angiogenic cytokines and matrix metalloproteinases. Circulation. 2005; 112: 1618-27.

22. Sieveking DP, Buckle A, Celermajer DS, Ng MK. Strikingly different angiogenic properties of endothelial progenitor cell subpopulations: insights from a novel human angiogenesis assay. Journal of the American College of Cardiology. 2008; 51: 660-8.

23. Cheng CC, Chang SJ, Chueh YN, Huang TS, Huang PH, Cheng SM, et al. Distinct angiogenesis roles and surface markers of early and late endothelial progenitor cells revealed by functional group analyses. BMC genomics. 2013; 14: 182.

24. Yin AH, Miraglia S, Zanjani ED, Almeida-Porada G, Ogawa M, Leary AG, et al. AC133, a novel marker for human hematopoietic stem and progenitor cells. Blood. 1997; 90: 5002-12.

25. Quirici N, Soligo D, Caneva L, Servida F, Bossolasco P, Deliliers GL. Differentiation and expansion of endothelial cells from human bone marrow CD133(+) cells. British journal of haematology. 2001; 115: 186-94.

26. Rehman J, Li J, Orschell CM, March KL. Peripheral blood "endothelial progenitor cells" are derived from monocyte/macrophages and secrete angiogenic growth factors. Circulation. 2003; 107: 1164-9.

27. Duan HX, Cheng LM, Wang J, Hu LS, Lu GX. Angiogenic potential difference between two types of endothelial progenitor cells from human umbilical cord blood. Cell biology international. 2006; 30: 1018-27.

28. Walter DH, Rittig K, Bahlmann FH, Kirchmair R, Silver M, Murayama T, et al. Statin therapy accelerates reendothelialization: a novel effect involving mobilization and incorporation of bone marrow-derived endothelial progenitor cells. Circulation. 2002; 105: 3017-24.

29. Loomans CJ, Wan H, de Crom R, van Haperen R, de Boer HC, Leenen PJ, et al. Angiogenic murine endothelial progenitor cells are derived from a myeloid bone marrow fraction and can be identified by endothelial NO synthase expression. Arteriosclerosis, thrombosis, and vascular biology. 2006; 26: 1760-7. 